\title{
Silica polymer bonding of stressed silica grains: An early growth of intergranular tensile strength
}

\author{
Rui Guo ${ }^{1}$, Tomasz Hueckel ${ }^{*}$ \\ Duke University, Durham, NC, United States
}

\section{H I G H L I G H T S}

- Micro-damaged amorphous silica grains under stress release silicic acid into near contact water.

- Within 3-4 weeks above initial concentration of 300 ppm, silicic acid polymerizes and forms polymer bridges between the grains.

- The force at rupture in a single polymer branch reaches up to $0.03 \mathrm{mN}$.

- The cumulative force at rupture of the polymer network between the grains reaches 1-1.5 mN.

- The latter value is $2-3$ times higher than an analogous capillary bridge force.

\section{A R T I C L E I N F O}

\section{Article history:}

Received 9 September 2014

Received in revised form 26 February 2015

Accepted 28 February 2015

Available online 17 March 2015

\section{Keywords:}

Soil bonding

Aging

Silica polymerization

Compressibility

Reservoir compaction

Pressure solution

\begin{abstract}
A B S T R A C T
Laboratory tests on microscale are reported in which millimeter-sized amorphous silica cubes were kept highly compressed in a liquid environment of de-ionized water solutions with different silica ion concentrations for up to four weeks. Such an arrangement simulates an early evolution of bonds between two sand grains stressed in situ. In-house designed Grain Indenter-Puller apparatus allowed measuring strength of such contacts after 3-4 weeks. Observations reported for the first time confirm a long-existing hypothesis that a stressed contact with microcracks generates silica polymers, forming a bonding structure between the grains on a timescale in the order of a few weeks. Such structure exhibits intergranular tensile force at failure of $1-1.5 \mathrm{mN}$ when aged in solutions containing silica ion concentrations of 200- to 500-ppm. The magnitude of such intergranular force is 2-3 times greater than that of water capillary force between the same grains.
\end{abstract}

(C) 2015 Elsevier Ltd. All rights reserved.

\section{Introduction}

The phenomenon of aging of granular soils has long been observed both in the laboratory and in the field. It consists in a time-dependent stiffening and strengthening of granular soil in saturated conditions over engineering time-scales. Several manifestations of aging were identified over the years. Anderson and Stokoe ${ }^{3}$ found that coarse sands exhibit a low-amplitude shear modulus that

\footnotetext{
* Corresponding author.

E-mail address: hueckel@duke.edu (T. Hueckel).

1 Currently with RA Consultants LLC, New York, NY.

increases linearly per log cycle time. In saturated sands, normalized tip resistance after blasting have been seen to increase with time by up to $18 \%$, whereas local friction decreased by $39 \%$ in the same time period. ${ }^{11}$ Under high pressure at room temperature, clean sand was found to have developed significant intergranular adhesion bonds. ${ }^{33} \mathrm{~A}$ time-delayed increase in stiffness of sand under sustained load was observed in dynamically compacted sands and is attributed to static fatigue. ${ }^{36}$ Field observations at Jebba Dam project in Nigeria showed a substantial increase in penetration resistance in sand, weeks after blasting or vibrocompaction, even though density changes in soil have completed much earlier. ${ }^{39}$ Similar results were observed in laboratory settings where cone penetration resistance 
of loose sand increased with time after blasting. ${ }^{16}$ Also in the laboratory, Hueckel et al. ${ }^{24,26}$ have shown a nearly $50 \%$ increase in stiffness of saturated core samples from 1000 and $3000 \mathrm{~m}$ depth subject for an over a 14 day aging under an in situ stress.

A hypothesis has been well-established that in dry granular soil, creep is a dominant aging phenomenon over engineering timescales. Based on field and laboratory results, it was postulated that a granular soil undergoes macrolocking, due to which grains become more efficiently packed under load, and microlocking, with surface roughness creep causing an increase in sliding resistance. ${ }^{35,47,31,8}$ Loading tests performed on an assembly of discs simulating a granular soil indicate a non-coaxiality of stress and strain-rate tensors and free rotating movements of particles under load. ${ }^{17}$ The presence of fines in dry sand is found to additionally increase creep strain and the aging rate confirmed via a discrete element model. . $^{50,49}$

However, in submerged conditions, the increase in penetration resistance of sand is higher than in dry conditions, which has been speculated to be due to dissolution and precipitation of salt and possibly silica. ${ }^{31}$ Precipitation of salt upon drying has been observed to cause a substantial increase of cohesion of granular material. ${ }^{14}$ Other sediments (chalk) also exhibit a delayed compressibility changes. ${ }^{41}$

The actual mechanisms of soil aging in submerged conditions still remain a puzzling topic. Various hypotheses have been proposed with less than preponderant supporting evidence. One of an early proposed hypotheses, supported by a laboratory evidence ${ }^{15}$ was that silica precipitates and forms a thin film of silicic acid gel on top of undisturbed silica layer which acts as cementing bonds that provide adhesion force between sand grains see also. ${ }^{39,31,24,22}$ Experiments showed that a thin film of silanol and silicic acid chains would develop on amorphous silica surfaces in the presence of water, ${ }^{48}$ see also. ${ }^{9,10}$ During prolonged loading of saturated sand, it is found that continual dissolution of minerals and some precipitation of carbonates and silica would occur. ${ }^{7}$ A study of silica dissolution in contact region between mica and quartz surfaces proposed that corrosion pits developed on quartz surfaces might allow a porous silica gel layer to be deposited. ${ }^{20}$ There is no clear understanding of the role of the presence of biofilms on soil stiffness. Oedometer tests conducted on dense Ottawa sand showed no influence of biofilms on the ultimate shear strength of the sand, ${ }^{42}$ whereas Banagan et al. ${ }^{4}$ claims that an addition of biofilms for a few days has caused a statistically significant increase in the shear strength of Ottawa sand. ${ }^{22} \mathrm{Hu}$ and Hueckel had recently proposed a coupled chemo-mechanical mechanism through which granular silica sand stiffens over engineering timescale under compression in the presence of water. The mechanism has been motivated by findings of Tada et al. ${ }^{52}$ that microcracks and micro-granulation generated near the stressed intergranular contacts an increase in the silica specific surface area, enhancing the silica dissolution by $25 \%$. Tada et al. postulated that the dissolved silica may cause supersaturation locally and precipitate and polymerize to form silica gel network that bonds neighboring silica grains together, thus stiffening the soil on a macroscopic scale. Indeed, preliminary experiments by the writers confirmed the presence of silica microstructures up to a few hundred micrometers in length growing near the stressed silica contacts in submerged conditions after 3 to 4 weeks of aging. Atomic Force Microscopy (AFM) pulling tests indicate that such silica polymers have tensile strength of the order of $100 \mathrm{nN}^{21}$

The objective of the current effort is to identify specific mechanism through which chemical reactions (spontaneous or induced) in geomaterials affect their macroscopic properties of strength and deformability. ${ }^{25,23,12,13}$ We have extended for that purpose our previous work, ${ }^{21}$ with the silica polymers observed growing near stressed contact regions of amorphous silica grains after 3 weeks in a liquid environment rich in silica ions. The main hypothesis behind this objective is that the outgrowth of the silica polymer provides with time the interparticle bonds that generate macro-scale cohesion responsible for the observed effects of aging. To limit the time of aging in laboratory, the fluid in the near contact environment was artificially brought to a sufficiently high concentration of silica ion (500, 400, 200 and $100 \mathrm{ppm}$ ), hence requiring only a limited amount of ions to create a saturated medium via dissolution to induce precipitation and gelation. ${ }^{46}$ Specifically, isolated silica aggregates of size in the order of 10 $\mathrm{nm}$ would form after a week in a supersaturated solution, while after two weeks or more a significant size gel network is observed. ${ }^{21}$

This paper presents new experimental evidence that links growth of silica polymers in engineering timescale correlates to the increase in tensile strength of the bond formed between two amorphous silica grains under prolonged compression in the presence of water. The size of silica polymers growing around stressed contact regions between two grains and their tensile strength are quantified. The overall increase in intergranular tensile strength of silicic granular material is estimated.

\section{Background}

Silica dissolution occurs in the presence of water via the following chemical reaction: ${ }^{30}$

$\mathrm{SiO}_{2}(s)+2 \mathrm{H}_{2} \mathrm{O}(l)=\mathrm{Si}(\mathrm{OH})_{4}(a q)$.

Because the soluble form of silica on the right hand side of the equation contains only one silicon atom, it is often named monosilicic acid. The most common form of monosilicic acid, as found in amorphous silica and crystalline silica, involves one silicon atom coordinated with four oxygen atoms. $\mathrm{OH}^{-}$ions act as catalyst in the hydration and dehydration of silica:

$\left(\mathrm{SiO}_{2}\right)_{x}+2 \mathrm{H}_{2} \mathrm{O}=\mathrm{Si}(\mathrm{OH})_{4}+\left(\mathrm{SiO}_{2}\right)_{x-1}$.

An early laboratory data on silica solubility indicate the solubility of $\mathrm{SiO}_{2}$ in crystalline silica as $6 \mathrm{ppm} .{ }^{30}$ More recent data show that the solubility of quartz at $25^{\circ} \mathrm{C}$ is around 10 ppm. ${ }^{44}$ The solubility of anhydrous nonporous amorphous silica oxide $\left(\mathrm{SiO}_{2}\right)$ is $70 \mathrm{ppm}$ at $25^{\circ} \mathrm{C} \cdot{ }^{28,18}$ However, most common amorphous silica exists in very small particles, 
forming porous aggregates with hydrated $\mathrm{SiOH}$ groups on the surface. The solubility of $\mathrm{SiO}_{2}$ in powders and gels made with amorphous silica ranges between 70 to $150 \mathrm{ppm}$ and remains largely unchanged between $\mathrm{pH} 2$ to 8 . However, solubility of amorphous silica in water increases drastically at higher $\mathrm{pHs}$. This is because at a higher $\mathrm{pH}$, soluble silica includes both the monomer mentioned above and silicate ion which is formed at higher $\mathrm{pH}$.

$\mathrm{Si}(\mathrm{OH})_{4}+\mathrm{OH}^{-}=\mathrm{Si}(\mathrm{OH})_{5}^{-}$.

At pH higher than 10.7, $\mathrm{Si}(\mathrm{OH})_{4}$ is converted to ions and all solid phase amorphous silica dissolves to form soluble silicate. ${ }^{2,30}$

In the presence of low concentration $\mathrm{NaCl}$ ions in water at neutral $\mathrm{pH}$, the surface reactivity of dissolved amorphous silica is enhanced and thus the dissolution rate of amorphous silica is found to be about 20 times higher. ${ }^{29}$ Because silica dissolution rate is very slow, supersaturation or undersaturation of silica in water can exist for long periods of time before reaching equilibrium by precipitation or dissolution. In supersaturated solution, silica changes to a sol in a process that takes weeks or months and such sols at a few hundreds ppm can remain stable. ${ }^{32}$ The dissolution rate of silica also varies widely depending on the types of silica. Silica surface bears an ionic charge which attracts hydroxyl ions in water and a silicon atom is exchanged into solution as a form of soluble silica. ${ }^{30}$

Generally, amorphous silica has a much higher dissolution rate than crystalline silica because amorphous silica has a more open surface structure, allowing more hydroxyl ions to replace silicon atoms. According to, ${ }^{30}$ fused glass (amorphous silica) has a rate of dissolution of $39 \mathrm{ppm} /$ day, whereas quartz has a dissolution rate of only $2.8 \mathrm{ppm} /$ day.

For the above reasons, with the intention to accelerate the processes, our choice is to adopt amorphous silica grains in our experiments. More importantly, naturally occurring quartz grains are enveloped by a layer of amorphous silica. ${ }^{51}$ This layer of amorphous silica is likely be the first to dissolve under compression in contact region between silica grains. ${ }^{1}$

As for the polymerization and gelation of silica, three steps can be identified during the process. ${ }^{30}$ First, monomers $\left(\mathrm{Si}(\mathrm{OH})_{4}\right)$ polymerize to form particles by condensing silanol groups into siloxane $(\mathrm{Si}-\mathrm{O}-\mathrm{Si})$ bonds in a reaction shown below:

$-\mathrm{SiOH}+\mathrm{HOSi}-=-\mathrm{SiOSi}-+\mathrm{H}_{2} \mathrm{O}$.

Second, the particles then grow by extending the siloxane bonds. Lastly, at low $\mathrm{pH}(<7)$ silica particles are able to aggregate into branches and ultimately into gel structures, as they possess little ionic charge. Notoriously, the presence of hardness ions (calcium or magnesium) or polyvalent ions, like iron or aluminum, greatly influence silica polymerization kinetics and the morphology of the formed material.

\section{Experimental method}

A silica cube indenter-puller previously described ${ }^{21}$ was used to conduct silica cube crushing and subsequent pulling experiments in solution.

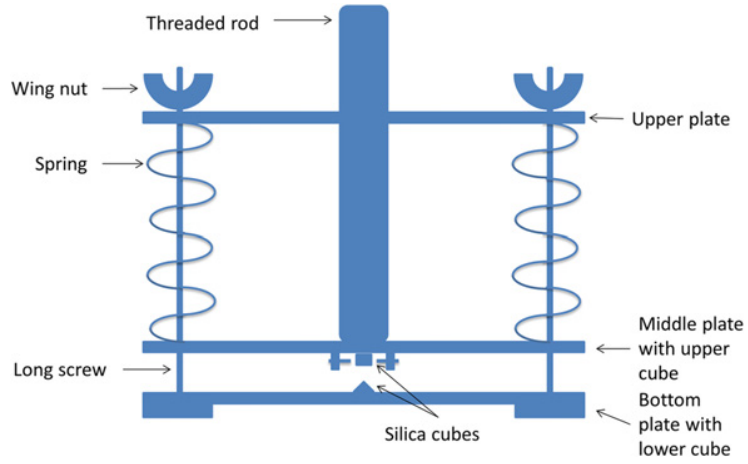

Fig. 1. Schematics of cube indenter-puller apparatus.

Silica cubes used in the aging-pulling experiments are made of unpolished amorphous quartz (Prism Research Glass Inc.) and blade-cut into $3 \mathrm{~mm} \times 3 \mathrm{~mm} \times 3 \mathrm{~mm}$ cubes to simulate common natural sand grains. Amorphous silica cubes are used rather than crystalline silica (quartz) ones, as explained earlier.

A solution containing silica ions is prepared to simulate soil pore fluid following the process described by Rimstidt and Barnes. ${ }^{45}$ Silicic acid powder $\left(\mathrm{H}_{2} \mathrm{SiO}_{3}\right.$; Fisher Scientific) is ionized in $5 \mathrm{M}$ sodium hydroxide solution and diluted with Nano-Pure Water (NPW) to silica ion concentrations ranging between $200 \mathrm{ppm}$ and $500 \mathrm{ppm}$. At the start of experiment, the $\mathrm{pH}$ value of the solution is brought down to 5.0 by adding $1 \mathrm{M}$ nitric acid to mimic the $\mathrm{pH}$ level in natural water.

As shown in Fig. 1, two silica cubes are attached to the bottom and middle plates, made of stainless steel, with the edge of one cube facing the flat face of the other. The cubes are pushed together by compressing springs (McMasterCarr) between the middle and top plates with a spring constant of $2960 \mathrm{~N} / \mathrm{m}$. After the apparatus is assembled, the springs are compressed by tightening the wingnuts on the top plate until up to $180 \mathrm{~N}$ of force is applied to the cubes. The indenter-puller with cubes is then placed in an air- and water-tight polypropylene container (McMasterCarr), submerged with solution containing silica ions. The compressed cubes are left to age for three to four weeks under a constant force. After the aging phase is completed, the apparatus is taken out of the container and attached to a load frame (Tinius Olsen H50K-S). The apparatus on the load frame is then lowered onto the analytic scale (Mettler Toledo AL204, $0.1 \mathrm{mg}$ precision) such that the load reading on the scale just reaches the maximum of 210 $\mathrm{g}$, indicating that the apparatus is now firmly in contact with the scale. Note that during this process the load frame exerts an additional compressive force of approximately $2 \mathrm{~N}$ to the silica cubes (equivalent to $1 \%$ increase from existing compressive force). The springs and top plate on the apparatus are then removed so that the two silica cubes are pressed together by the $2 \mathrm{~N}$ compressive force generated between the load frame and the scale.

Pulling is kinematically controlled. It is initiated with a speed of $0.020 \mathrm{~mm} / \mathrm{min}(0.3333 \mu \mathrm{m} / \mathrm{s})$ for the first $15 \mathrm{~min}$, or until the apparent weight reading on the scale steadily decreases, after which the speed is increased to $0.100 \mathrm{~mm} / \mathrm{min}$ to $0.200 \mathrm{~mm} / \mathrm{min}(1.667 \mu \mathrm{m} / \mathrm{s}$ to 
$3.333 \mu \mathrm{m} / \mathrm{s}$ ) for the remainder of the pulling process, until the cubes are visibly separated with no water bridge between cubes. Apparent weight measurements on the analytic scale are recorded every second for the duration of the pulling experiment.

After the pulling experiment, images of cube surfaces were taken using Environmental Scanning Electron Microscopy (ESEM, FEI XL30). Small amount of water vapor was injected into the microscope chamber to slow down the drying process of silica gel growing on cubes as it also helps reducing the charging effect of electrons on silica surfaces.

A series of control experiments have been performed to assess the effects of scale sensitivity, effect of silica surface solid-solid contacts, and water capillary bridge forces between silica cubes on apparent weight measurements, as described further on.

\section{Results}

\subsection{General framework}

In a standard procedure, apparent weight (AW) readings recorded by the electronic scale were plotted against the change in separation between the cubes, or the relative displacement of the polymer structure ends for each cubepulling experiment. Initial points, with extremely high AW readings are ignored because such AW values are a result of the load-frame pre-loading of the cubes against the scale to keep the cubes pressed together. During initial pulling phase, the AW reading would reach a plateau where the load-frame is raised sufficiently to not to exert any downward force on the scale and the apparent weight-separation curve starts to exhibit a relatively continuous pattern. AW data are hence measured and processed (i.e. force differences were calculated) from then onward in what will be referred to as the partial-contact (via polymer) phase. In practical terms, during pulling the apparent weight measured by the scale decreases as a result of the uplift of the top cube and the lower cube attached to the former one by the polymer network.

In the partial-contact phase, the upward displacement of the upper cube is very limited. Nevertheless, four, practically consecutive, types of events are hypothesized to take place. First, direct interlocked contacts between asperities and cracks of the two cubes are unlocked at the smallest displacement. Subsequently, as the upper cube is pulled further away from the bottom cube, polymers attached to both cubes are unraveled and stretched. Thirdly, when the individual links of the polymer being stretched reach their individual tensile strength and break, or become detached from the grain substrate, a corresponding drop in total force is registered. This process continues until no unbroken polymer links remain attached. At such point no bonding remains between the cubes, except for that of the capillary water bridge stretched between the cubes.

Apparent weight vs displacement curves was closely examined for any sudden drops in apparent weight recorded, as such drops would possibly indicate the existence of a silica polymer or gel cluster linking the cubes and having a non-negligible stiffness. The curves when looked

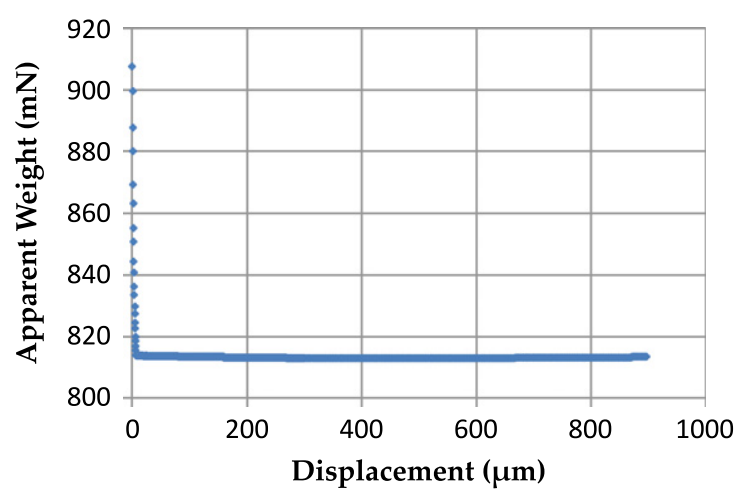

Fig. 2. Plot of AW vs displacement for experiment in $500 \mathrm{ppm}$ solution after 3 weeks aging.

at a sufficiently small scale exhibit a series of characteristic events of stick-and-slip. Such behavior is encountered in many progressively damaged materials, oftentimes composed of multiple parallel substructures, which successively fail, while the whole structure can still accept an increasing load (see e.g. failure of a wired cable, or shear failure at an interface with many sheared-off asperities). The force difference between all the neighboring end-points of an individual force-jump were measured and plotted against separation displacement. Furthermore, summation of all individual force jumps is used to estimate the maximum intergranular pulling force a silica polymer or gel structure can withstand between two silica cubes, or in other terms the silica gel tensile strength can be estimated from the curve.

The results of pulling experiments conducted on silica cubes aged under compression for 3 weeks in solutions with different silica concentrations are shown below.

\subsection{Aging in 500 ppm solution}

Silica cubes were compressed in solutions with the initial silica ion concentration of $500 \mathrm{ppm}$ and $\mathrm{pH}$ value 5.0 for 3 weeks. After aging was complete, pulling was performed at $0.020 \mathrm{~mm} / \mathrm{min}$ speed and the overall apparent mass vs displacement curve is shown in Fig. 2.

The initial point of the graph in Fig. 2 coincides with a force at the moment of the force stabilization, after the detachment of the interlocked asperities. The partial-contact phase of the apparent weight vs displacement curve is redrawn in a different scale in Fig. 3 after removing the points corresponding to the above mentioned detachment of the interlocked asperities.

It can be noted that most pronounced changes in the apparent weight occur in the early stages of pulling. More than a 1000 instances of an abrupt decrease in apparent weight of different amounts were recorded. The force difference amounts for individual force jumps vs displacement are shown in Fig. 4 providing the values of tensile force changes exhibited in the partial-contact phase. The maximum decrease in force between two neighboring points on the curve was $0.0265 \mathrm{mN}$.

Fig. 5 presents an ESEM image taken at $50 \times$ magnification of a cube grain showing the growth of silica gel over 


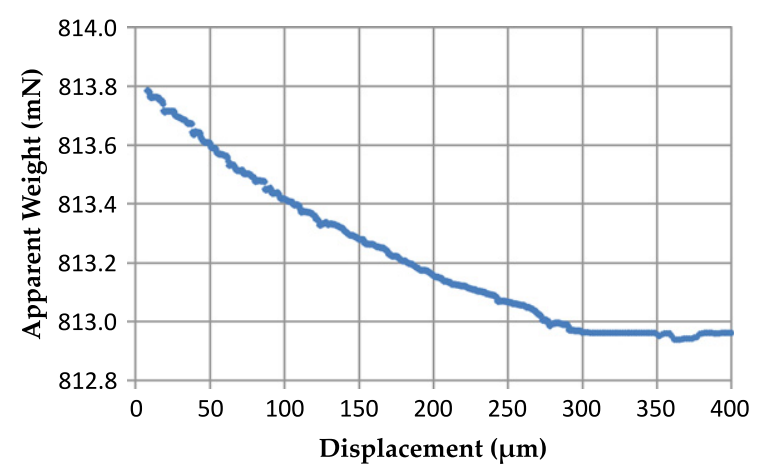

Fig. 3. Partial-contact phase of AW vs displacement curve, 500 ppm solution 3 weeks.

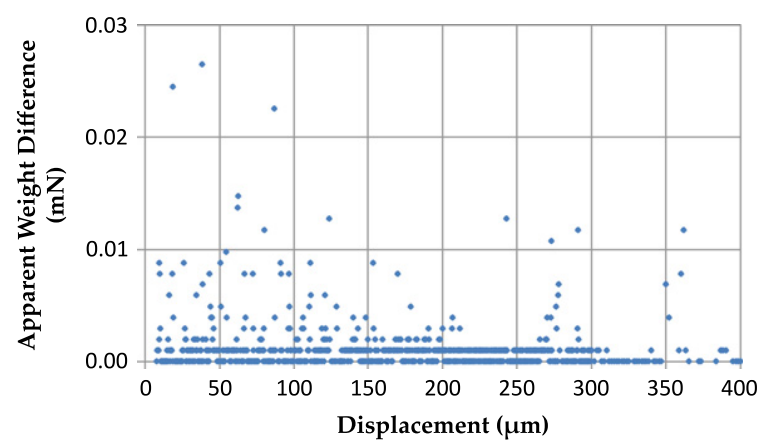

Fig. 4. Difference in AW between neighboring data points in partialcontact phase, 500 ppm solution 3 weeks.

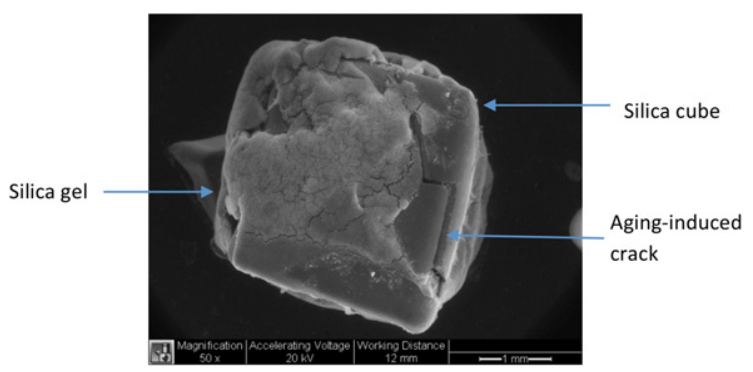

Fig. 5. Silica grain after aging in $500 \mathrm{ppm}$ solution for 3 weeks, 50X magnification in ESEM.

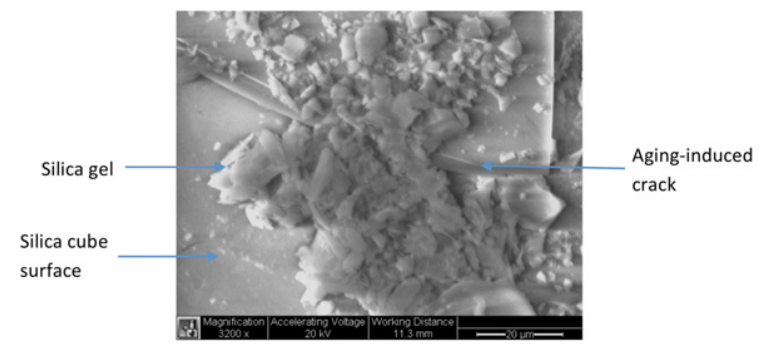

Fig. 6. Grain surface with cracks after aging in compression in 500 ppm solution for 3 weeks, $3200 X$ magnification.

a crack. A detail at $3200 \times$ magnification level is shown in Fig. 6 and it is an example of a site of a precipitate joining two parts of the crashed silica cube together.

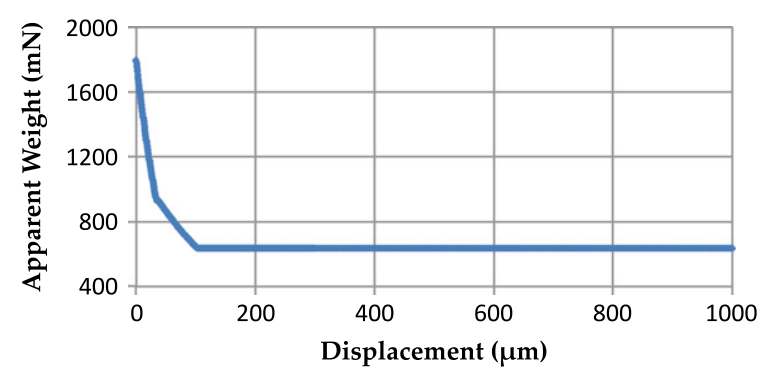

Fig. 7. Plot of AW vs displacement for experiment in $400 \mathrm{ppm}$ solution after 3 weeks aging.

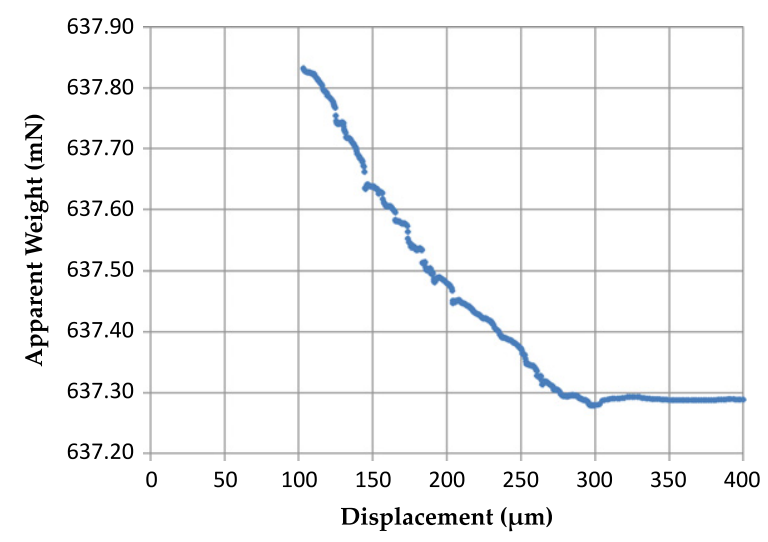

Fig. 8. Partial-contact phase of AW vs displacement curve, 400 ppm solution 3 weeks.

An additional experiment was conducted on a specimen for which the aging phase lasted for 4 weeks and its net total tensile force was measured and compared to that of the 3-week aging experiment. Net total tensile force is defined as the accumulated measured tensile force exerted by silica gel structures between silica cubes during the entire pulling procedure. It is an estimate of the total tensile force generated by silica gels between two silica grains after aging. This force is calculated by adding up all the positive Apparent Weight differences as shown in Fig. 4. Net total tensile forces integrated over the total duration of partial contact phase in the two experiments have been $0.9395 \mathrm{mN}$ for 3 week aging, and $1.3318 \mathrm{mN}$ for 4 week aging.

\subsection{Aging in $400 \mathrm{ppm}$ solution}

After aging in solution with initial $400 \mathrm{ppm}$ silica ion concentration at $\mathrm{pH} 5.0$ for 3 weeks, a pulling experiment was conducted and the apparent weight vs displacement curve is shown in Fig. 7. Multiple instances of sudden drop in apparent weight can be seen in the early stages of the partial-contact phase shown in Fig. 8. The magnitudes of tensile force differences between neighboring points on the partial-contact phase curve were computed and are shown in Fig. 9. The maximum magnitude of the force differences is $0.0268 \mathrm{mN}$. The net tensile force integrated over time in $400 \mathrm{ppm}$ solution after 3 weeks is $0.6679 \mathrm{mN}$. 


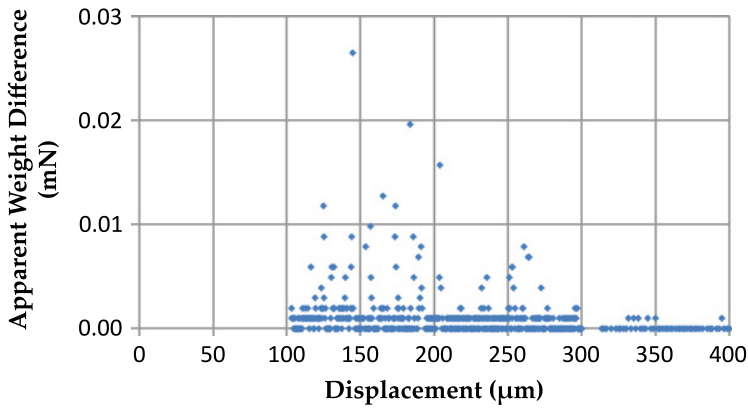

Fig. 9. Difference in AW between neighboring data points in partialcontact phase, 400 ppm solution 3 weeks.

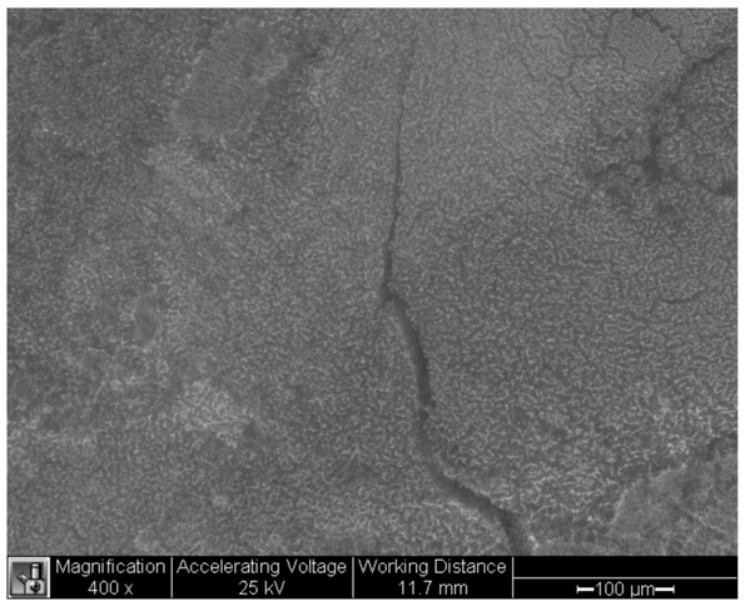

Fig. 10. Silica grain surface, covered with silica gel after aging in $400 \mathrm{ppm}$ solution for 3 weeks, 400X magnification.

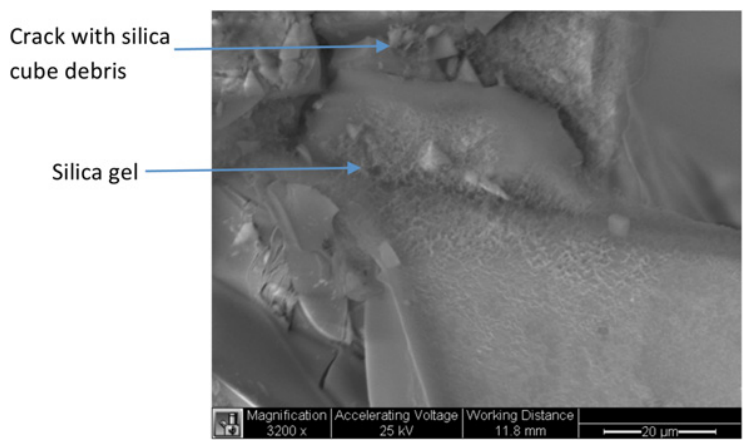

Fig. 11. Silica gel growing over cracks and asperities near stressed contact, after aging in $400 \mathrm{ppm}$ solution for 3 weeks, 3200X magnification.

Figs. 10 and 11 present ESEM images taken at magnification of $400 \times$ and $3200 \times$ of the contact edge of a silica cube. Clusters of silica gel can be seen growing near new cracks and asperities, joining small debris to the main silica cube body.

\subsection{Aging in 300 ppm solution}

The overall pulling force of the silica cubes after 3 weeks of aging under compression is plotted in Fig. 12 and the partial-contact phase of the experiment is shown in

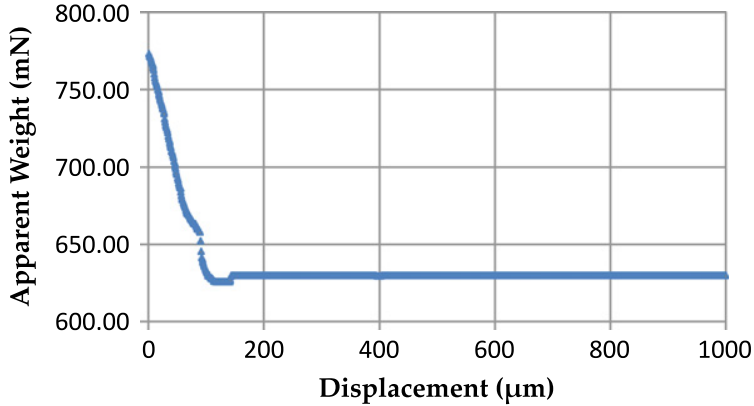

Fig. 12. Plot of AW vs displacement for experiment in $300 \mathrm{ppm}$ solution after 3 weeks aging.

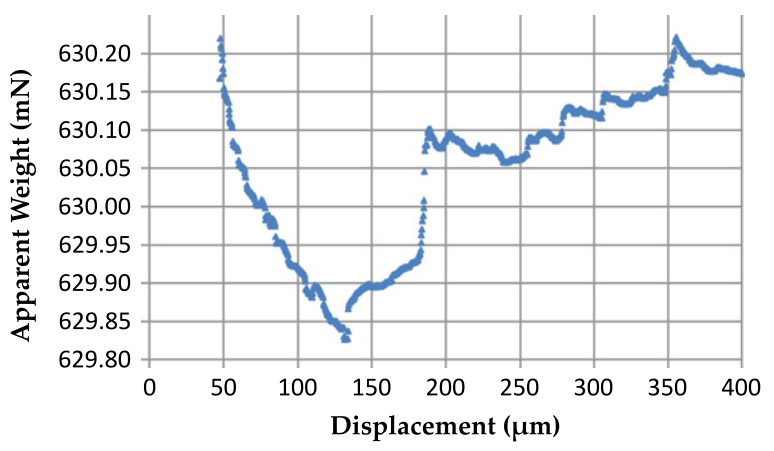

Fig. 13. Partial-contact phase of AW vs displacement curve, $300 \mathrm{ppm}$ solution 3 weeks.

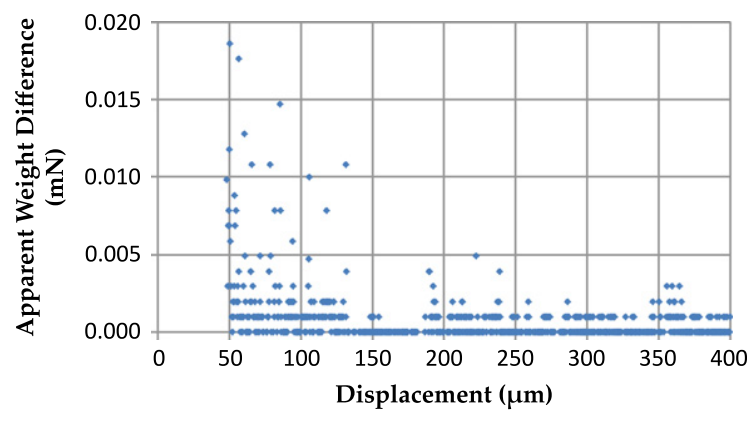

Fig. 14. Difference in $\mathrm{AW}$ between neighboring data points in partialcontact phase, 300 ppm solution 3 weeks.

Fig. 13. The tensile force difference curve was shown in Fig. 14. The maximum magnitude of force difference was $0.0186 \mathrm{mN}$. There were more than 300 instances where the force difference before force started decreasing at $134 \mu \mathrm{m}$ displacement. SEM images (Figs. 15 and 16) showed a significant extent of silica gel growth on cube surfaces near contact area. The net total tensile force measured in 300 ppm solution after 3 weeks is $0.6423 \mathrm{mN}$.

\subsection{Aging in 200 ppm solution}

The overall apparent weight vs displacement curve of pulling experiment conducted after cubes were compressed and aged in $200 \mathrm{ppm}$ solution for 3 weeks is shown in Fig. 17. A portion of the apparent weight data is missing 


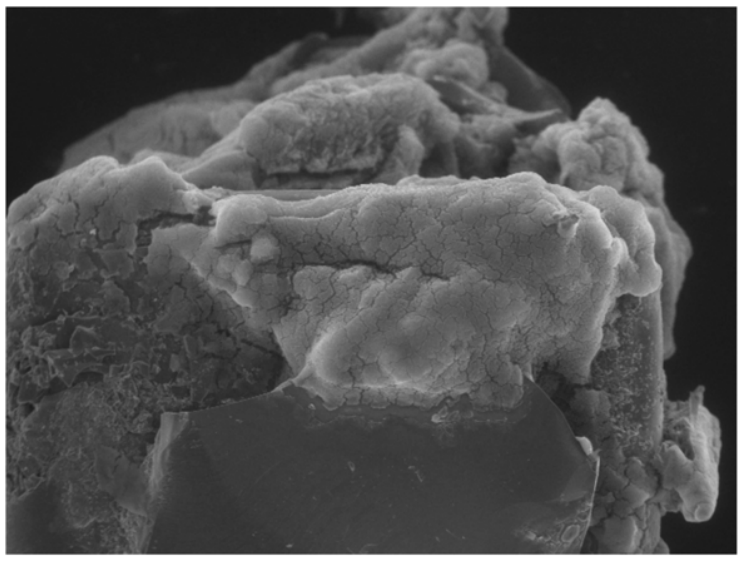

Fig. 15. Silica surface near stressed contact region, after aging in $300 \mathrm{ppm}$ solution for 3 weeks.

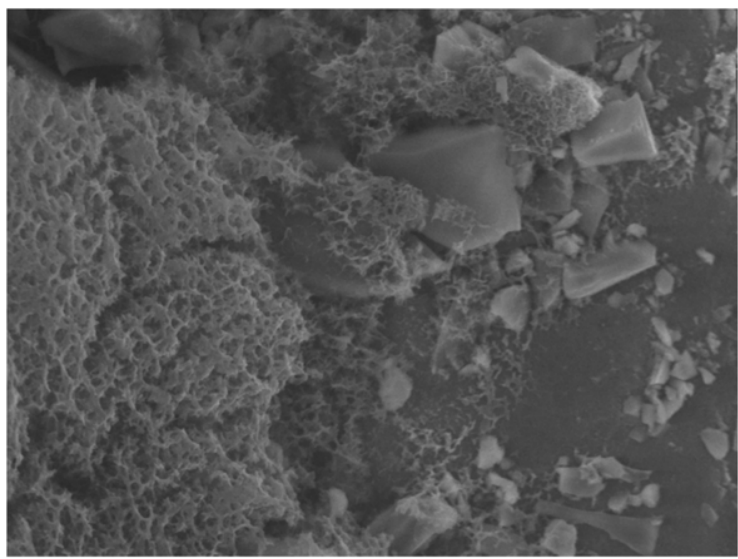

Fig. 16. Local view of silica polymer network bonding debris together near contact region, 300 ppm solution 3 weeks.

between displacements 298 and $357 \mu \mathrm{m}$ but it did not affect evaluation of apparent weight changes in the partialcontact phase. The partial-contact phase was shown in Fig. 18, where more than 700 instances of abrupt drops in the apparent weight were observed. Fig. 19 shows the tensile force differences between neighboring points of the apparent weight vs displacement curve in the partialcontact phase. The largest tensile force difference measured was $0.0157 \mathrm{mN}$. The net integrated tensile force measured during the entire process in $200 \mathrm{ppm}$ solution after 3 weeks was $0.5953 \mathrm{mN}$.

\subsection{Control experiments}

Five different control experiments were conducted to assess the effects of the weighing scale sensitivity, the influence of the direct silica solid-solid surface contact the effect of the water capillary bridge force between the silica cubes on the apparent weight measurements and finally, the effect of the rate of the deformation (displacement) rate. All five control experiments were conducted with an aging time of one minute. In the first control experiment, two silica cubes were brought in contact in dry condition

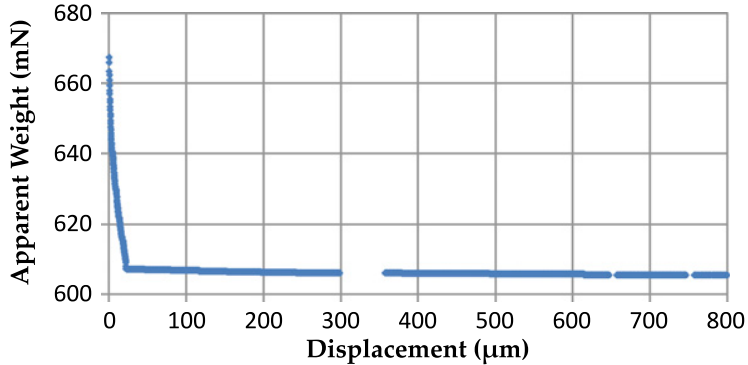

Fig. 17. Plot of AW vs displacement for experiment in $200 \mathrm{ppm}$ solution after 3 weeks aging.

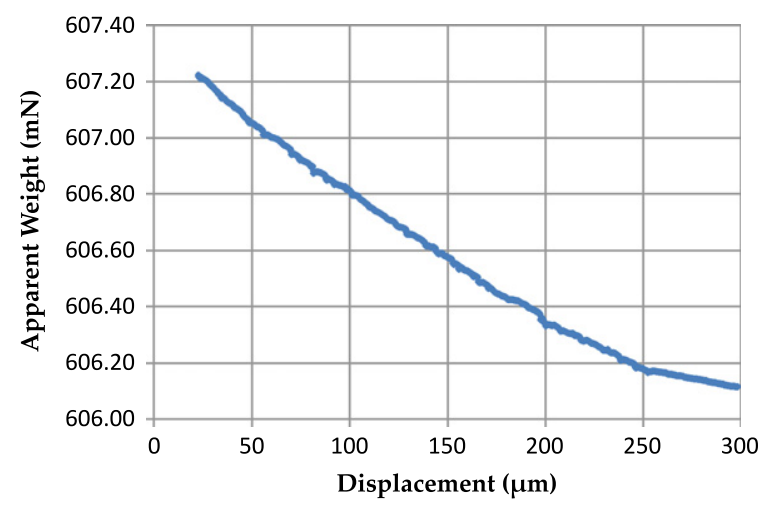

Fig. 18. Partial-contact phase of AW vs displacement curve, 200 ppm solution 3 weeks.

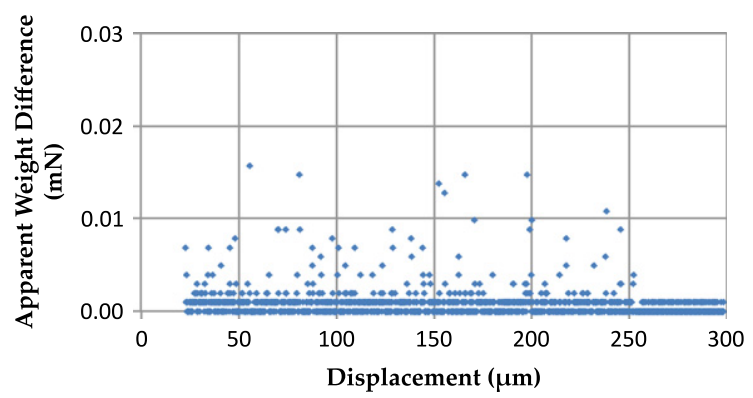

Fig. 19. Difference in AW between neighboring data points in partialcontact phase, 200 ppm solution 3 weeks.

with no force applied, before they were pulled apart, thus excluding the effects of stress and silicic acid fluid at intergranular contact. In the second control experiment, the cubes were compressed in dry condition with 150 $\mathrm{N}$ force, so that the intergranular contact was stressed without the presence of silicic acid fluid. A visible crack can be seen on the upper cube. In both control experiments in dry conditions, weight equilibrium has been reached very quickly. No stick-and-slip behavior, that means no jumps in the apparent weight, were recorded.

In the third control experiment, silica cubes were in contact in solution with silica ion concentration of 500 ppm with no force applied in order to study only the effect of silica fluid on the intergranular contact, or in other terms the effect of the capillary force. No aging was allowed. The result of subsequent pulling is shown in Fig. 20. The apparent weight vs displacement curve is very 


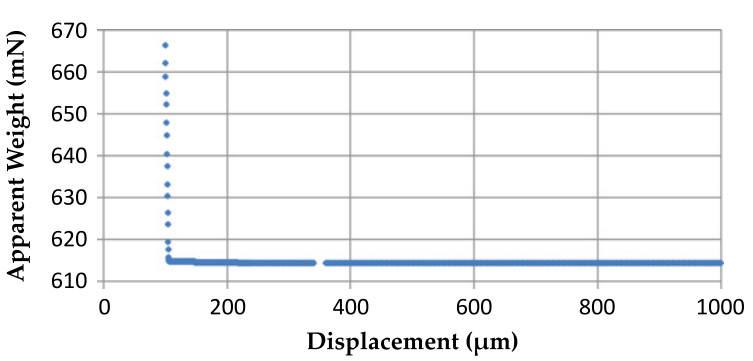

Fig. 20. Plot of AW vs displacement for control experiment in unstressed saturated $(500 \mathrm{ppm})$ conditions.

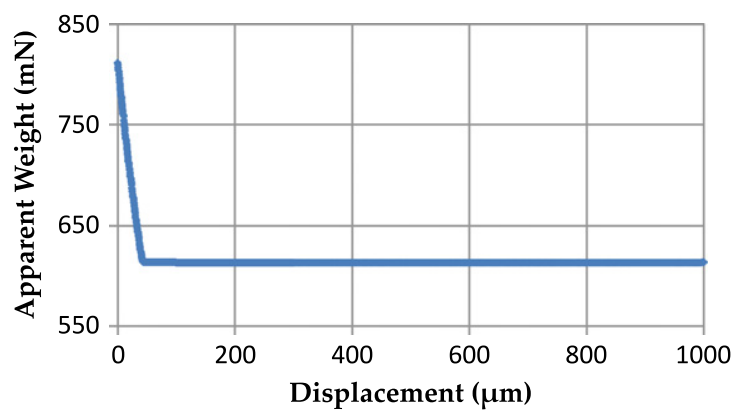

Fig. 21. 21 Plot of AW vs displacement for control experiment in stressed saturated $(500 \mathrm{ppm})$ conditions.

smooth with no significant drop, in the AW measurements. Fluctuations in apparent weight readings (the highest at $0.0088 \mathrm{mN}$ ) may have originated from the floor vibration. Weight minimum was reached after a displacement of $300 \mu \mathrm{m}$ between cubes. The magnitude of the total force drop was $0.0088 \mathrm{mN}$. This value is believed to be the resultant capillary force attracting the cubes.

In the last control experiment, two silica cubes were compressed with a $150 \mathrm{~N}$ force applied, and aged in 500 ppm solution for one minute, before the upper cube was pulled away, thus replicating the standard experiment procedure, but without the effect of aging. The resulting apparent weight vs displacement curve (Fig. 21) shows an overall smooth process. The initial unloading part of the curve in stressed saturated conditions is more gradual than unstressed saturated conditions, possibly due to surface interlocking between cubes. Only two small drops in measurements at 0.0118 and $0.0108 \mathrm{mN}$ were measured, possibly due to surface interlocking under pressure. The minimum weight reading was reached after a separation displacement of $300 \mu \mathrm{m}$.

For $500 \mathrm{ppm}$ no-damage control-experiment, total capillary force was $0.3403 \mathrm{mN}$. For $500 \mathrm{ppm}$ damaged control-experiment, total capillary force was $0.4590 \mathrm{mN}$.

Finally, an experiment on a sample aged for 3 weeks was conducted with pulling at a half the usual speed, namely at $0.010 \mathrm{~mm} / \mathrm{min}$. Net total tensile force measured during this experiment was $0.8669 \times 10^{-3} \mathrm{~N}$.

\section{Discussion}

We have previously confirmed that silica polymers grow between two compressed silica cubes, as originally suggested by Denisov and Reltov. ${ }^{15}$ The silica polymer growth after aging for a few weeks concentrated near contact region under compression with a local damage. ${ }^{21}$ The silica cube indenter-puller was thus designed to measure the intergranular tensile force that such a polymer structure develops between silica cubes upon an increasing cube separation. As the load frame slowly pulls the upper cube away from the bottom cube, silica polymers attached to both cubes near contact region are stretched, exerting a tensile force that lifts up the lower cube sitting on an electronic scale. As a result, a sharply fluctuating apparent weight measurement is recorded on an otherwise consistently downward-trending apparent weight vs displacement curve. During the stretching of the polymer, the scale would record episodes of a higher-than-normal decrease in apparent weight, followed by a slight increase in weight as the polymer is stretched too far and locally broken. A positive force difference indicates the scale recorded a finite drop in apparent weight, whereas a negative force difference on the curve indicates that the scale recorded an increase in apparent weight. From measuring the magnitudes and lengths of the finite weight drops, polymer size and tensile strength can be estimated since the rate of displacement is known. Adding up the magnitudes of all the apparent weight drops occurring between 0 to $400 \mu \mathrm{m}$ of cube (separation) displacement in the experiment, the net tensile force applied by silica polymers growing between two silica cubes during aging has been estimated.

As the top cube is pulled away from the bottom cube, water capillary effect between cubes weakens continuously. Thus, the apparent weight of the bottom cube recorded by the scale would increase continuously during pulling experiment. This becomes observable at the end of the partial-contact phase, as the apparent weight of the bottom cube begins to increase slowly. The total intergranular tensile force is to be calculated by combining the change in capillary force during pulling and the net tensile force in the polymer network in the partial-contact phase.

Control experiments conducted to determine machine error and water capillary effect on the apparent weight measurements during pulling with $500 \mathrm{ppm}$ silica ion concentration, but with no aging exhibit the apparent weight vs displacement curves that are very smooth. Capillary forces are attractive forces arising at the contact between the interface of air, water and solid, and are primarily dependent on the surface tension of the liquid and the curvature of air/liquid interface. Changes in capillary forces after $400 \mu \mathrm{m}$ separations were measured for cubes with unstressed contact and cubes with stressed contact amounting to $0.3403-$ and $0.4590-\mathrm{mN}$, respectively. In the stressed control experiment, cube surfaces were severely damaged with cracks observable by the naked eye. In other experiments, damages to cubes were much more local with micro asperities and small debris generated through contact. Thus, the approximate capillary force adopted was the average of the two values obtained in control experiments, hence equal to $0.4 \mathrm{mN}$. As it was seen in the experiments with pure water capillary bridges, the total intergranular force between two spherical silica grains tends to decrease with the kinematically driven extension of the separation (see e.g. ${ }^{34,37}$ ). The force either decreases monotonically to 
Table 1

Number and distribution of events for experiments in different silica ion concentration solution.

\begin{tabular}{|c|c|c|c|c|c|}
\hline $\begin{array}{l}\text { Range of AW } \\
\text { difference }(\mathrm{mN})\end{array}$ & $\begin{array}{l}\text { No. of events for } \\
\text { 3-week-aging in } 500 \\
\text { ppm solution }\end{array}$ & $\begin{array}{l}\text { No. of events for } \\
\text { 4-week-aging in } 500 \\
\text { ppm solution }\end{array}$ & $\begin{array}{l}\text { No. of events for } \\
\text { 3-week-aging in } 400 \\
\text { ppm solution }\end{array}$ & $\begin{array}{l}\text { No. of events for } \\
\text { 3-week-aging in } 300 \\
\text { ppm solution }\end{array}$ & $\begin{array}{l}\text { No. of events for } \\
\text { 3-week-aging in } 200 \\
\text { ppm solution }\end{array}$ \\
\hline $0<x \leq 0.010$ & 457 & 1092 & 307 & 332 & 776 \\
\hline $0.010<x \leq 0.020$ & 24 & 15 & 5 & 9 & 7 \\
\hline $0.020<x \leq 0.030$ & 8 & 2 & 1 & 0 & 0 \\
\hline $0.030<x \leq 0.040$ & 0 & 0 & 0 & 0 & 0 \\
\hline $0.040<x \leq 0.050$ & 3 & 0 & 0 & 0 & 0 \\
\hline
\end{tabular}

zero, or the bridge breaks and there is a force jump to zero. The magnitude of the force does depend on the size of grain and size of the initial gap between the two grains, but for the grains of $8 \mathrm{~mm}$ diameter, the order of magnitude of the capillary force is about $0.5 \mathrm{mN}$, which is the order of the forces measured in our experiments.

Apparent weight vs displacement curves generally reach a minimum for displacements of the cubes between 300 to $400 \mu \mathrm{m}$, indicating a complete separation of the cubes at this stage. After the minimum of force is reached, the cubes are completely separated and weight measurements are affected by capillary effect only. The magnitude of the capillary force decreases continuously as separation between the cubes grows larger until finally capillary bridge breaks down. As such, the apparent weight of silica cube tends to increase after complete separation towards the end of the pulling procedure.

\subsection{Intergranular tensile force}

In the experiments where cubes were aged in $500 \mathrm{ppm}$ solution for three weeks, three weeks but with a half speed during pulling, and for four weeks again at a standard rate of $20 \mu \mathrm{m} / \mathrm{min}$, the maximum tensile force measured were $0.9395-, 0.8669-$ and $1.3318-\mathrm{mN}$ respectively. The tensile failure force for four weeks aging was by more than $30 \%$ higher than that after three weeks. Thus it is possible that at high silica concentration, the polymerization process within the first three and four weeks progresses substantially with the time of the process.

The force distribution in specific tensile force ranges measured during pulling are shown in Table 1.

It is interesting to note the test at half rate of pulling (down from 20 to $10 \mu \mathrm{m} / \mathrm{min}$ ), produces the tensile force at failure that is about $8 \%$ smaller. It suggests that the silica polymer is a visco-elasto-plastic structure, but with a relatively weak rate sensitivity. The distribution of AW difference during half-speed pulling experiment is shown in Table 2. Most notably the number of events was ten times lower as far as low amplitude events are considered, whereas the number of the events of higher amplitude is of the same order during faster and slower pulling.

High force differences occurred in the early separation phase, with magnitudes of $0.0245-, 0.0265-$, and $0.0226 \times$ $10^{-3} \mathrm{~N}$ respectively, for the above identified cases. This is possibly due to polymer links that being stressed most and broken in the early separation process are the most robust, possibly shortest, of the entire population. This point deserves a closer attention. SEM images of cube surfaces taken after pulling experiment showed evidence
Table 2

Number and distribution of events for experiments in $500 \mathrm{ppm}$ solutions for 3-week aging at $0.01 \mathrm{~mm} / \mathrm{min}$ speed of pulling.

\begin{tabular}{ll}
\hline Range of AW difference $(\mathrm{mN})$ & $\begin{array}{l}\text { No. of events for half-speed } \\
\text { pulling experiment aged in } \\
500 \text { ppm solution for } 3 \text { weeks }\end{array}$ \\
\hline $0<x \leq 0.0100$ & 57 \\
$0.0100<x \leq 0.0200$ & 8 \\
$0.0200<x \leq 0.0300$ & 4 \\
$0.0300<x \leq 0.0400$ & 7 \\
$0.0400<x \leq 0.0500$ & 6 \\
\hline
\end{tabular}

that silica polymers were indeed growing on cube surfaces and bridging between cracks (Fig. 6 ).

In the experiment where cubes were aged in $400 \mathrm{ppm}$ solution under compression for 3 weeks, the total maximum intergranular tensile force recorded was $0.6679 \mathrm{mN}$, which is nearly $30 \%$ less than at $500 \mathrm{ppm}$. Nevertheless, SEM images of cube surfaces taken after pulling (Figs. 10 and 11) show also at $400 \mathrm{ppm}$ a massive gel growth on surfaces near the contact region, connecting debris with the main cube body.

In $300 \mathrm{ppm}$ solution, after 3 weeks aging, the maximum tensile force was $0.6423 \mathrm{mN}$, slightly smaller than those in $400 \mathrm{ppm}$ solution, but visibly smaller than in higher, i.e. $500 \mathrm{ppm}$ silica ion concentration solutions. SEM images of silica cubes in $300 \mathrm{ppm}$ solution were taken after 3-week aging (Figs. 15 and 16) and show that the boundaries of cracked patterns on silica cube surfaces matched the boundaries of thicker gel structures growing on the same surface. It suggests that the cracked patterns on silica cubes are silica gel residue after drying in the SEM chamber. The image also suggests that at $300 \mathrm{pm}$ the region of bonding was smaller than in 400- and 500-ppm. The tensile force measured in the $300 \mathrm{ppm}$ experiment reached a peak at $134 \mu \mathrm{m}$ of separation and started decreasing after that (Fig. 13). That type of softening of the polymer was not seen in other tests at different silica concentrations.

In the experiment where cubes were aged under compression for 3 weeks in 200 ppm solution, net intergranular tensile force was $0.5953 \mathrm{mN}$, again less than that at all higher concentrations. Interestingly, the cut-off distance between cubes when no further change in apparent weight can be observed was $250 \mu \mathrm{m}$, longer than those in 300and 400-ppm solutions. Cut-off distance is defined as the separation distance between cubes beyond which no further change in apparent weight was observed on the scale. It is an indication of maximum force that the polymer may sustain. Unfortunately, the force was not measured beyond the separation of $300 \mu \mathrm{m}$.

Based on the experiments, it can be concluded that as concentration of silica ions in solution increased, so did 


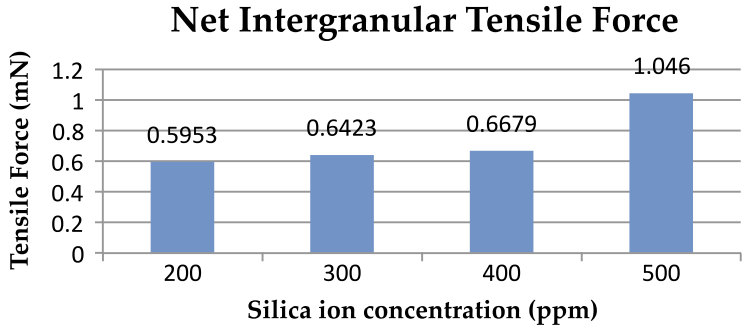

Fig. 22. Net intergranular tensile force measured in cube indenter-puller experiments at different $\mathrm{Si}$ ion concentrations.

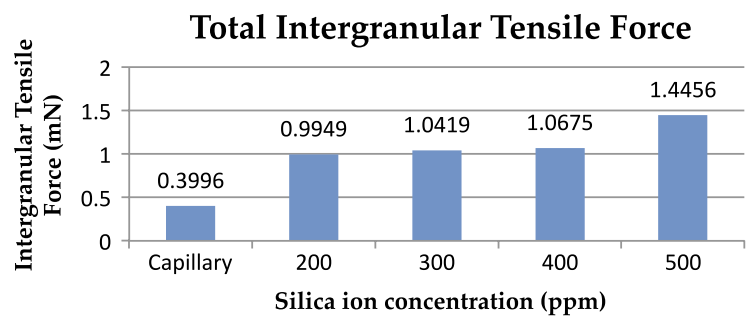

Fig. 23. Total intergranular tensile force measured between grains in pulling experiments at different Si ion concentrations.

\section{Cut-off Separation in Pulling Experiments}

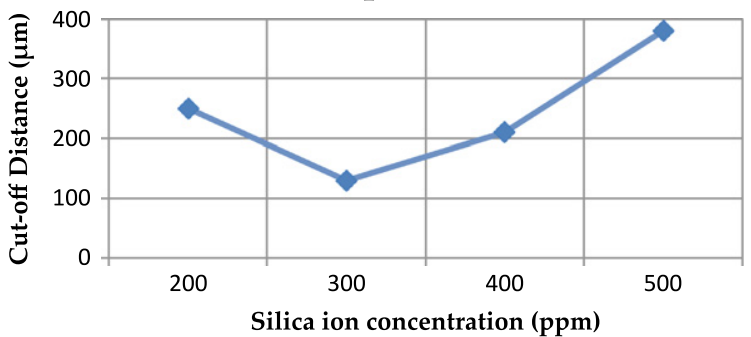

Fig. 24. Cut-off separation in pulling experiments after aging in solutions containing various $\mathrm{Si}$ ion concentrations.

maximum intergranular tensile force in the silica gel on cubes during the separation increase, as shown in Fig. 22. This is most likely because less silica gel was formed at lower concentration around contact region between silica cubes. We can establish that the intergranular tensile force that silica gel can exert on grains in a solution with slightly over-saturated silica ions is in the order of $1 \mathrm{mN}$.

The maximum total intergranular tensile force expected to be generated by completely submerged polymer network, that is without capillary contribution is calculated by combining net intergranular tensile force and change in (attractive) capillary force. The results are shown in Fig. 23.

\subsection{Silica polymer network size}

The cut-off separation, at which the total intergranular force becomes zero represents in a sense the maximum length to which a polymer network may be extended between the grains. As seen in the SEM images collected after the network failure, the polymer is still attached to

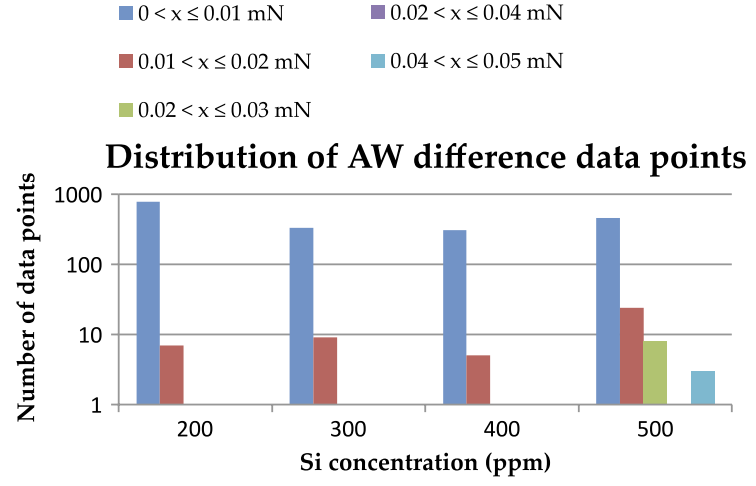

Fig. 25. Distribution of force difference data points in pulling experiments after aging for 3 weeks in different Si ion concentration solutions.

the grain surface. This confirms our hypothesis that failure of the polymer network takes place by a breakage of the individual links, rather than via detachment from the grain substrate. A summary of cut-off separation vs silica ion concentration is shown in Fig. 24. Apart from 200 ppm solution, there is a consistent trend that higher silica ion concentration in solution yielded the polymer networks that could be extended the most. The maximum separation to which the polymer could be extended is $0.4 \mathrm{~mm}$. The result at $200 \mathrm{ppm}$ has been confirmed in a few repeated tests. At this time we do not offer any hypothesis we could confirm based on an independent test.

An additional information about the evolution of the silica polymer during pulling experiments is obtained from the distribution of the number of force difference amounts belonging to a given range of force drops presented in a semi-log scale shown in Fig. 25. It is worth to remind that measurement points are taken every second. Each point with positive magnitude is believed to represent the strength of an individual silica polymer link that has been stretched and broken during pulling. Points with negative magnitudes meant no polymer was being stretched during that second.

At lower concentrations, all data points with positive magnitudes were less than $0.02 \mathrm{mN}$, whereas at higher concentrations a small number of points with large magnitudes have been detected. This observation suggests that a small number of robust polymer links was growing at contact regions only in high silica ion concentration solutions. At lower concentrations, a gel network of uniformly low strength links would grow between grains. That clearly refers to polymers developed within 3-4 weeks.

\subsection{Error analysis}

In control experiments, standard deviation of the capillary force effect plus the local asperities interlocking effect was $0.00705 \mathrm{mN}$. Data obtained in the control experiments with no stress applied in wet conditions were used to estimate the water capillary effect and machine errors on the force measurement. Standard deviation of the mean capillary effect was $0.00498 \mathrm{mN}$. Using the data from all three experiments conducted in $500 \mathrm{ppm}$ solutions, the standard deviation of the net intergranular tensile force 


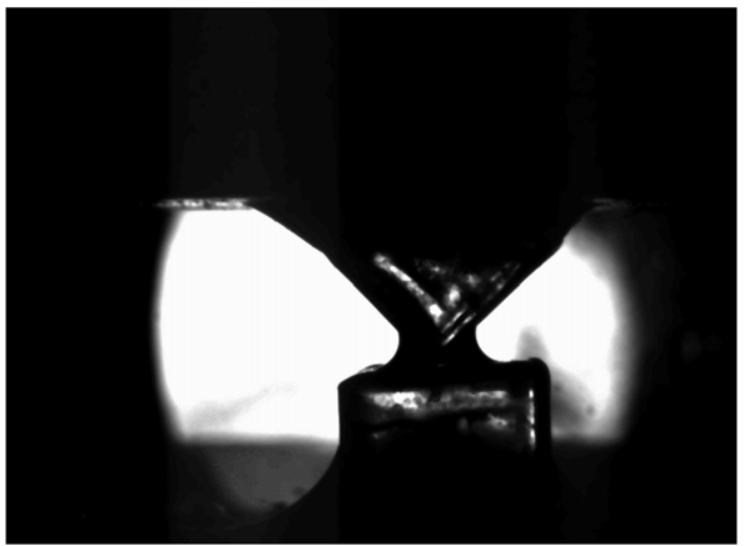

Fig. 26. Water capillary bridge between two silica grains during control pulling experiment.

is calculated as $0.2042 \mathrm{mN}$, hence about two orders of magnitude larger.

The capillary force can be calculated by measuring the radii of curvature of the gorge forming between the two grains at the equator plane and the external meridian curvature using the Laplace equation,

$\Delta p=\gamma\left(\frac{1}{r_{g}}+\frac{1}{r_{e x t}}\right)$

whereas

$F_{C}=\Delta p \cdot \pi r_{g}^{2}+2 r_{g} \pi \cdot \gamma$

where $\Delta p$ is Laplace pressure, $\gamma=0.0496 \mathrm{~N} / \mathrm{m}$ is the experimentally measured surface tension of water, $r_{g}$ is the radius of curvature of the gorge at the equator plane, $r_{e x t}$ is the radius of external meridian curvature, and $F c$ is capillary force. ${ }^{27}$ Radius of curvature can be estimated by measuring the radius of the best-fit-circle on the water capillary bridge (Fig. 26).

To assess the effect of changing capillary force on intergranular bonding force of silica polymers, capillary force at the start of the partial-separation phase is calculated. Subsequently, at the cut-off distance, corresponding capillary force is calculated again based on images similar to those shown in Fig. 26. It is found that the change in capillary force, $\Delta F c$ is $0.34 \mathrm{mN}$, which is approximately $15 \%$ smaller than the capillary force measured experimentally. The discrepancy is expected because the formulae assumed an axisymmetric configuration whereas in this experiment, width of capillary bridge along the grains' contact edges is longer.

\section{Conclusions}

Following our previous experiments ${ }^{21}$ that show silica polymers of a consistent strength growing in an intergranular space submerged in water, in this paper we have measured the strength of such inter-particle bonds. Several sets of experiments were run with a different pre-test aging, which is simply an immersion in water with a prescribed concentration of silicic acid under a constant applied external load. The concentration varied between 200- and 500-ppm. $120 \mathrm{ppm}$ is a concentration closest to that of silica found in natural water. Higher concentrations were investigated as well, as locally silica concentration may reach very high values, depending on micro-scale flowconnectivity, or lack of it. High initial concentration is also useful in order to accelerate the kinetics of the precipitation process without qualitatively affecting silica precipitation and polymerization, which would occur eventually at local asperities naturally at lower silica ion concentrations but over much longer time scales.

We conclude that tensile strength of the precipitated and polymerized silica between two amorphous silica grains reaches significant values within relatively short periods of time. These values for 200 and $500-\mathrm{ppm}$ of silica, reach the amount of $1-1.5 \mathrm{mN}$. Such values are two to three times higher than capillary forces arising in the same system. The latter observation informs us that silica polymers generated (or enhanced) in the process of an intergranular damage may play a significant role in timedependent enhancement of the material compressibility and/or strength. Macroscopic compressibility is known to be dependent on local intergranular tensile and rotational strength Oda and Iwashita ${ }^{40}$. Thus we may assert that the early hypothesis of Denisov and Restov ${ }^{15}$ and Chadwick et al. (1987), see also, ${ }^{39}$ about silica polymer formation at grain contact being a leading mechanism of early aging has been experimentally confirmed for the first time.

Good understanding of the evolution of compressibility is of paramount importance in assessing sediment subsidence and reservoir compaction in petroleum engineering, as it has been a subject of controversies and debate for some time, see. ${ }^{19,6,5,43}$ This finding is also relevant to the question of short-term aging of soils for geotechnical use, and a proper conduction of oedometer compression tests to better represent soil compressibility in situ. ${ }^{24}$

There is a host of new questions raised by the presented work. The first among them is, whether the observed intergranular silica polymer bonding spontaneously building at the intergranular damage site, is sufficient to account for the time dependent strengthening of sediments observed by Hueckel et al. ${ }^{24,26}$ The current answer is yes, the measured forces are 2-3 times higher than capillary force, classically believed to be responsible for the apparent cohesion increase upon desaturation. Another question refers to further evolution of the polymer bridges and their strength, their possible solidification and possible interactions with other processes. It is clearly realized that in natural systems, there is more than one mechanism that may contribute to the time dependent strengthening of sediments. The others are: capillary forces, ${ }^{38}$ calcite precipitation, ${ }^{12}$ and porosity reduction (see e.g. ${ }^{25}$ ) and precipitation of salts during drying. ${ }^{14}$

\section{Acknowledgments}

The authors acknowledge the support of US National Science Foundation grant no. 0700294 of the Civil, Mechanical and Manufacturing Innovation Division, Geomechanics and Geomaterials Program, and, in part, of a grant no. 470000007918/OR1 from ENI S.p.A. (Rome, Italy). 


\section{References}

[1] Aase NE, Bjorkum PA, Nadeau PH. The effect of grain-coating microquartz on preservation of reservoir porosity. Aapg Bull Am Assoc Pet Geologists Aapg 1996;80(10):1654-1673.

[2] Alexander GB, Heston WM, Iler RK. The solubility of amorphous silica in water. J Phys Chem 1954;58(6):453-455.

[3] Anderson D, Stokoe K. Shear modulus: a time-dependent soil property. 1978:66-90.

[4] Banagan BL, Wertheim BM, Roth MJS, Caslake LF. Microbial strengthening of loose sand. Lett Appl Microbiol 2010;51(2): $138-142$.

[5] Baù D, Ferronato M, Gambolati G, Teatini P. Basin-scale compressibility of the Northernern Adriatic by the radioactive marker technique. Geotechnique 2002:52(8):605-616.

[6] Cassiani G, Zoccatelli. Toward a reconciliation between laboratory and in situ measurements of soil and rock compressibility. Land Subsidence. Proceedings of the Sixth International Symposium on Land Subsidence, (SISOLS2000), vol. 2. In: Carbognin L, ed. Padova, Italy: La Garsignola; 2000:3-15.

[7] Baxter CDP, Mitchell JK. Experimental study on the aging of sands. J Geotech Geoenviron Eng 2004;130(10):1051-1062.

[8] Bowman ET, Soga K. Creep, ageing and microstructural change in dense granular materials. Soils Found 2003;43(4):107-117.

[9] Chadwick OA, Hendricks DM, Nettleton WD. Silica in duric soils: I. A depositional model. Soil Sci Soc Am J 1987;51:975-982.

[10] Chadwick OA, Hendricks DM, Nettleton WD. Silicain duric soils: II. Mineralogy. Soil Sci Soc Am J 1987;51:982-985.

[11] Charlie WA, Rwebyogo MFJ, Doehring DO. Time-dependent cone penetration resistance due to blasting. J Geotech Eng 1992;118(8): $1200-1215$

[12] Ciantia MO, Hueckel T. Weathering of submerged stressed calcarenites: chemo-mechanical coupling mechanisms. Geotechnique 2013 63(9):768-785.

[13] Ciantia M, Castellanza R, Di Prisco C, Hueckel T. Effects of mineral suspension and dissolution on strength and compressibility of soft carbonate rocks. Eng Geol 2015;184:1-18.

[14] Delenne JY, Soulie F, El Youssoufi MS, Radjai F. From liquid to solid bonding in cohesive granular media. Mech Mater 2011;43(10): 529-537.

[15] N.Y. Denisov, B.F. Reltov, The influence of certain processes on the strength of soils. In: Proceedings of the 5th International Conference of Soil Mechanics and Foundation Engineering vol. 1. 1961: 75-78.

[16] Dowding C, Hryciw R. A Laboratory study of blast densification of saturated sand. J Geotech Eng 1986;112(2):187-199.

[17] Drescher A, de Jong GDJ. Photoelastic verification of a mechanical model for the flow of a granular material. J Mech Phys Solids 1972; 20(5):337-351

[18] Fournier RO, Rowe JJ. The solubility of amorphous silica in water at high temperature and high pressures. Am Mineral 1977;62: 1052-1056, 1977

[19] Gambolati G, Teatini P, Tomasi L. Stress-strain analysis in productive gas/oil reservoirs. Int J Numer Anal Methods Geomech 1999;23: $1495-1519$.

[20] Greene GW, Kristiansen K, Meyer EE, Boles JR, Israelachvili JN. Role of electrochemical reactions in pressure solution. Geochim Cosmochim Acta 2009;73(10):2862-2874.

[21] Guo R, Hueckel T. Growth of polymer microstructures between stressed silica grains: a chemo-mechanical coupling. Geotechnique 2013;63(4):322-330

[22] Hu LB, Hueckel T. Coupled chemo-mechanics of intergranular contact: Toward a three-scale model. Comput Geotech 2007;34(4): 306-327.

[23] Hueckel T. Reactive plasticity for clays during dehydration and rehydration. Part 1: concepts and options. Int J Plast 2002;18(3): 281-312.

[24] Hueckel T, Cassiani G, Tao Fan, Pellegrino A, Fioravante V. Aging of oil/gas-bearing sediments, their compressibility, and subsidence. J Geotech Geoenviron Eng 2001;127(11):926-938.

[25] Hueckel T, Pellegrini R, Del Olmo C. Constitutive properties of thermo-elasto-plastic behavior of deep carbonatic clays. Int J Numer Anal Methods Geomech 1998;22(7):549-576.
[26] Hueckel T, Cassiani G, Prévost J.H, Walters D.A, Field derived compressibility of deep sediments of the northern Adriatic. In: Barends FBJ, et al. eds. Proceedings, Seventh International Symposium on Land Subsidence (Sisols 2005), Shanghai, China. October 2005, Special Volume 2005:35-50.

[27] Hueckel T, Mielniczuk B, El Youssoufi M.S, Micro-scale study of rupture in desiccating granular media. In: Geo-Congress; Stability and Performance of Slopes and Embankments. San Diego, CA. 2013: 808817.

[28] Kennedy GC. A portion of the system silica-water. Econ Geol 1950; 47:629-653.

[29] Icenhower JP, Dove PM. The dissolution kinetics of amorphous silica into sodium chloride solutions: effects of temperature and ionic strength. Geochim Cosmochim Acta 2000;64(24):4193-4203.

[30] Iler RK. The Chemistry of Silica: Solubility, Polymerization, Colloid and Surface Properties, and Biochemistry. John Wiley \& Sons, Inc.; 1979.

[31] Joshi R, Achari G, Kaniraj SR, Wijeweera H. Effect of aging on the penetration resistance of sands. Can Geotech J 1995;32(5):767-782.

[32] Krauskopf KB. Dissolution and precipitation of silica at low temperatures. Geochim Cosmochim Acta 1956;10(1-2):1-26.

[33] Lee KL. Adhesion bonds in sands at high pressures.J Geotech Eng Div 1977; 103(8):908-913

[34] Lian G, Thornton C, Adams MJ. A theoretical study of the liquid bridge forces between two rigid spherical bodies. J Colloid Interface Sci 1993; $161: 138-147$.

[35] Mesri G, Feng T, Benak J. Postdensification penetration resistance of clean sands. J Geotech Eng 1990;116(7):1095-1115.

[36] Michalowski RL, Nadukuru SS. Static fatigue, time effects, and delayed increase in penetration resistance after dynamic compaction of sands. J Geotech Geoenviron Eng 2012:138(5):564-574.

[37] Mielniczuk B, El Youssoufi MS, Sabatier L, Hueckel T. Rupture of a liquid bridge between two grains due to its evaporation. Acta Geophysica 2014;62(5):1087-1108 http://dx.doi.org/10.2478/s11600-0140225-6.

[38] Mielniczuk B, Hueckel T, El Youssoufi MS, Evaporation-induced evolution of the capillary force between two grains. Granular Matter 2014;16(5):815-828 http://dx.doi.org/10.1007/s10035-0140512-6.

[39] Mitchell JK, Solymar ZV. Time-dependent strength gain in freshly deposited or densified sand. J Geotech Eng ASCE 1984;110(11): $1559-1576$.

[40] Oda M, Iwashita K. Mechanics of Granular Materials - an Introduction. Rotterdam: A.A. Balkema; 1999

[41] Papamichos E, Brignoli M, Compaction of soft weak rocks due to water flooding, society of petroleum engineers. SPE 47389 1998; $1-7$.

[42] Perkins SW, Gyr P, James G. The influence of biofilm on the mechanical behavior of sand. Geotech Test J 2000;23(3):300-312

[43] Prevost JH, Pecker A, Hueckel T. Fundamentals of modeling subsidence, 2005. Land Subsidence. Special Volume: Multi-disciplinary Assessment of Subsidence in the Ravenna. Area. In: Barends FBJ, et al., eds. Rotterdam, The Netherlands: Millpress; 2005:51-65, 2005.

[44] Rimstidt JD. Quartz solubility at low temperatures. Geochim Cosmochim Acta 1997;61(13):2553-2558.

[45] Rimstidt J, Barnes H. The kinetics of silica-water reactions. Geochim Cosmochim Acta 1980;44(11):1683-1699.

[46] Rubin CJ. A Novel Apparatus for the Study of Intergranular Silica Microstructures. [M.Sc. thesis] Durham, NC: Duke University; 2009.

[47] Schmertmann JH. The Mechanical aging of soils. J Geotech Eng 1991; 117(9):1288-1330.

[48] Vigil G, Xu Z,H, Steinberg S, Israelachvili J. Interactions of Silica Surfaces. J Colloid and Interface Sci 1994;165(2):367-385

[49] Wang YH, Tsui KY. Experimental Characterization of Dynamic Property Changes in Aged Sands. J Geotech Geoenviron Eng 2009; 135(2):259-270

[50] Wang YH, Xu D, Tsui KY. Discrete element modeling of contact creep and aging in sand. Journal of Geotechnical and Geoenvironmental Engineering 2008:134(9):1407-1411.

[51] Worden RH, et al. Amorphous silica nanofilms result in growth of misoriented microcrystalline quartz cement maintaining porosity in deeply buried sandstones. Geology 2012;40(2):179-182.

[52] Tada R, Maliva R, Siever R. A new mechanism for pressure solution in porous quartzose sandstone. Geochim Cosmochim Acta 1987;51(9): $2295-2301$. 